\title{
Knowledge, attitude, and practice of people toward epilepsy in a South Indian village
}

\author{
Balaji Krishnaiah, Seenivasan P. Alwar' ${ }^{1}$ Lakshmi N. Ranganathan ${ }^{2}$ \\ Department of Neurology, Penn State Hershey Medical Center, Hershey, Pennsylvania, USA, ${ }^{1}$ Department of Social and Preventive Medicine, \\ Government Stanley Medical College and Hospital, ${ }^{2}$ Department of Neurology, Madras Medical College, Chennai, Tamil Nadu, India
}

\begin{abstract}
Introduction: People living with epilepsy continue to suffer from enacted or perceived stigma that is based on myths, misconceptions, and misunderstandings that have persisted for many years. In the last decade, there has been an increase in individual literacy rate and increased access to technology in rural population. However, it is unclear if this has any effect on knowledge, attitude, and practice (KAP) attitude toward epilepsy. Objective: Our primary aim is to evaluate KAP toward epilepsy. In addition, we also estimated the prevalence of stroke and epilepsy in rural South India. Materials and Methods: Using a 14-item questionnaire, we assessed KAP toward epilepsy and identified determinants of inappropriate attitudes toward people with epilepsy and 10-item questionnaires to assess the prevalence of epilepsy and stroke among 500 randomly selected populations in a Pattaravakkam village (Tamil Nadu, India). Results: About $87.7 \%$ of the people had heard or read about epilepsy. Negative attitudes appeared to be reinforced by beliefs that epilepsy is hereditary (23.1\%), kind of insanity (22.6\%), or as contagious (12.0\%). The knowledge about the clinical characteristics and first aid to a person during a seizure was $25.8 \%$. About $36.5 \%$ of people think that society discriminates people with epilepsy. Moreover, our prevalence study showed that $8.7 \%$ people are suffering from epilepsy and $3.7 \%$ had stroke previously and at the day of survey, the stroke prevalence is 3.3\%. Conclusion: Even with increased literacy, technology, and communication devices, the KAP of people toward epilepsy is relatively low. General public education campaigns and specific school education campaigns children should be encouraged to increase the KAP toward epilepsy. The prevalence and pattern of epilepsy and stroke is on the higher side in the village of Pattaravakkam. Future research regarding the value of targeted education in improving KAP will be worthwhile.
\end{abstract}

Key words: Epilepsy, knowledge, attitude and practice, social stigma

\section{Introduction}

People with epilepsy are socially discriminated because of public attitudes, misunderstandings, and defensive behavior. Recently conducted knowledge, attitude, and practice (KAP) in developed country showed positive attitude, ${ }^{[1-3]}$ but in developing countries, it is still highly a stigmatizing disease. ${ }^{[4-6]}$

In the last decade, there has been an increase in individual literacy rate and increased access to

\section{Address for correspondence:}

Dr. Balaji Krishnaiah, Penn State Hershey Medical Center,

30 Hope Drive, Hershey, Pennsylvania 17033, USA.

E-mail: balajikrishnaiah@gmail.com

\begin{tabular}{|l|l|}
\hline \multicolumn{2}{|c|}{ Access this article online } \\
\hline Quick Response Code: & Website: \\
\hline & www.ruralneuropractice.com \\
\cline { 2 - 3 } & \\
\hline
\end{tabular}

technology and communication devices in rural population. However, it is unclear if this has any effect on KAP toward epilepsy. Our primary aim is to evaluate KAP toward epilepsy. In addition, we also estimated the prevalence of stroke and epilepsy in rural South India.

\section{Materials and Methods}

This study was performed in the village of Pattaravakkam near Chennai, South India. It is comparable to any rural setting in India by having same level of literacy, health awareness, and health services. In this village, we performed a house-to-house survey for screening of

This is an open access article distributed under the terms of the Creative Commons Attribution-NonCommercial-ShareAlike 3.0 License, which allows others to remix, tweak, and build upon the work non-commercially, as long as the author is credited and the new creations are licensed under the identical terms.

\section{For reprints contact: reprints@medknow.com}

How to cite this article: Krishnaiah B, Alwar SP, Ranganathan LN. Knowledge, attitude, and practice of people toward epilepsy in a South Indian village. J Neurosci Rural Pract 2016;7:339-40. 
cases; in addition to using uniform diagnostic criteria for epilepsy and stroke.

\section{Area of study}

The study was conducted in a village hamlet named Pattaravakkam located in Kattankulathur taluk, Kanchipuram district of Tamil Nadu in South India [Figure 1]. It is a village Panchayat comprising three villages namely Pattaravakkam, Thenur, and Ilanthoppe. It is a rural area having a population of 2500. It has one primary health center and one Government Primary School.

\section{Study population}

The prevalence study was conducted among 500 people selected by stratified random selection from the village, whereas the KAP study was conducted only in people aged above 15 years.

\section{Study design}

The study was a two-staged door-to-door survey consisting of (a) preparatory stage and (b) survey stage.

\section{Preparatory stage}

One month before the start of survey, 20 medical students from Government Stanley Medical College under our leadership were trained at our institute on survey techniques, orientation to seizure disorders, method of interview, and recording of data. The most common false beliefs are related to mental retardation, mental illness, and emotional disturbances in patients. ${ }^{[7]}$ In extreme cases, epilepsy could be perceived as possession by an evil spirit. ${ }^{[8]}$ The objectives and rationale of the survey were discussed with the local villagers, responsible seniors,

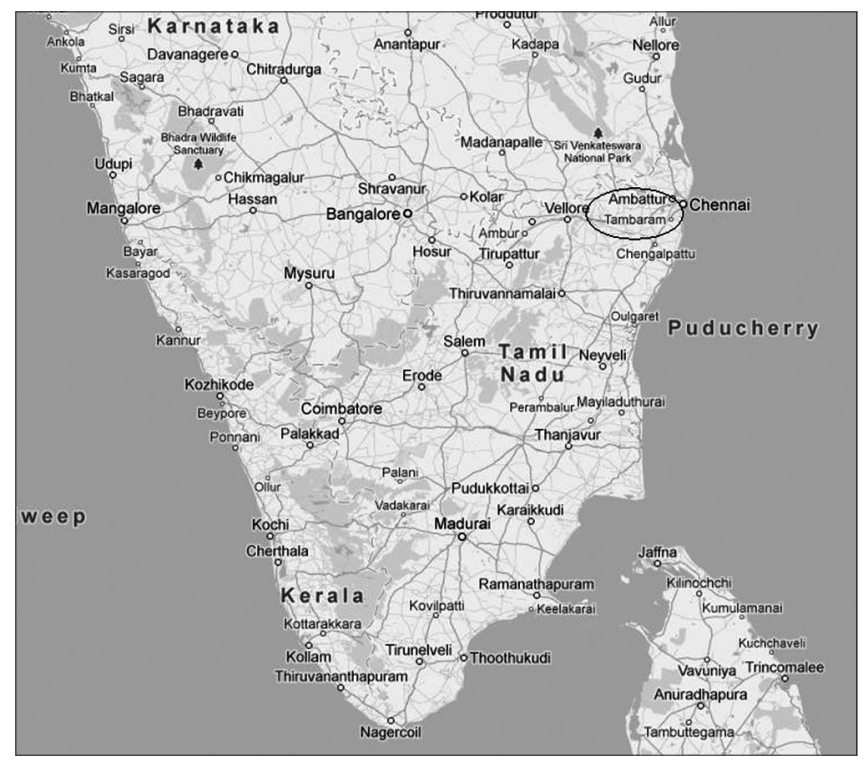

Figure 1: Area of study: Pattaraivakkam village, Kanchipuram dist., Tamil Nadu, India. Courtesy: Google maps village chairman, and officials to enlist their cooperation and support. These measures yielded excellent public compliance ensuring high level of case ascertainment.

\section{Survey stage}

The actual survey was carried out in two phases.

\section{Phase I (screening phase)}

The first step of the investigation involved a door-to-door survey, which was carried from August through October 2008 in this survey, 20 medical students under our leadership carried out the survey and filled the questionnaire in local Tamil language by interviewing the people.

\section{Phase I/ (diagnostic phase)}

All of the collected data were analyzed by three neurologists experienced in epilepsy who searched for positive cases. Individuals with responses of epilepsy and stroke were requested to have an examination by the neurologists. The examinations were carried out on the day of the survey in a nearby Government Primary School.

\section{Knowledge, attitude, and practice study}

KAP studies have now become an integral part of community management of chronic illnesses associated with high level of stigma such as leprosy and epilepsy. ${ }^{[9]}$ The KAP study for epilepsy was also conducted on the same day along with the prevalence study.

\section{Questionnaire}

The survey questionnaire contained 14 questions [Appendix 1]. All the questions were with simple yes or no responses. The questionnaire was also designed to cover KAP toward epilepsy. The questionnaire we used had been field tested in a pilot study.[10] The questionnaire was divided into three parts. The first part was developed to obtain the demographic characteristics of the population. The questions in the other part were developed to gather information on public understanding on attitudes toward epilepsy and to find the prevalence of epilepsy and stroke. The questionnaire was designed to ensure maximum sensitivity. The sensitivity and specificity of the questionnaire were $100 \%$ and $72 \%$, respectively. ${ }^{[10]}$

\section{Results}

The demographic details of the study population are presented in Table 1 . The responses to the questions are summarized in Table 2. The distribution of age, gender, and educational qualification is shown in 
Table 1: Demographic characteristics of the respondents $(n=500)$

\begin{tabular}{lc}
\hline Demographic & $\boldsymbol{n}(\%)$ \\
\hline Gender & $231(46.2)$ \\
Male & $269(53.8)$ \\
Female & \\
Age group & $195(39)$ \\
$<20$ & $90(18)$ \\
$20-34$ & $155(31)$ \\
$35-49$ & $50(10)$ \\
$>65$ & \\
Educational level & $119(23.8)$ \\
None & $186(37.1)$ \\
Primary & $173(34.6)$ \\
Secondary & $3(0.6)$ \\
Graduate & \\
Employment status & $348(69.6)$ \\
Unemployed (women, elderly) & $84(16.7)$ \\
Semi-skilled & $60(12.0)$ \\
Unskilled & $5(1.0)$ \\
Professional &
\end{tabular}

Table 2: Questionnaire used for the pilot study

\begin{tabular}{lcc}
\hline Questionnaire & Yes & No \\
\hline Have u ever heard a disease called epilepsy & 87.7 & 12.3 \\
Is epilepsy a mental illness & 22.6 & 77.4 \\
Is epilepsy a hereditary disease & 23.1 & 76.9 \\
Is epilepsy a contagious disease & 12.0 & 88.0 \\
Do you think that epilepsy is caused by ancestors sin & 21.6 & 78.4 \\
Do you think epilepsy is a hindrance to happy life & 42.3 & 57.7 \\
Can epilepsy patient lead a normal sexual life & 54.8 & 45.2 \\
Do you think epilepsy affects education of a person & 57.0 & 43.0 \\
Do you think epilepsy patients can be employed & 49.0 & 51.0 \\
Do you think society discriminates against persons with & 36.5 & 63.5 \\
epilepsy & & \\
Do you think allopathic treatment is beneficial for epilepsy & 80.3 & 19.7 \\
Do you think ayuvedic treatment is beneficial for epilepsy & 42.357 .7 \\
Would you allow your child to play with an epileptic child & 64.4 & 35.6 \\
\hline
\end{tabular}

Figures 2 and 3. The majority of respondents were unemployed $69.6 \%$ which include females and older people [Table 1] and was earning $<1000$ rupees/month $(40.5 \%)$. Most of the people aged $<20$ years and in the third decade. The answers to the question "How would you attend a person during a seizure?" are provided in Figure 4.

From our study, it has been found out that about $23.8 \%$ of the study population are illiterate. Majority of this group comprises females. Literacy has been described as the ability to read for knowledge and write coherently and thinks critically about the written word. Literacy can also include the ability to understand all forms of communication, be it body language, pictures, video, or sound (reading, speaking, listening, and viewing).

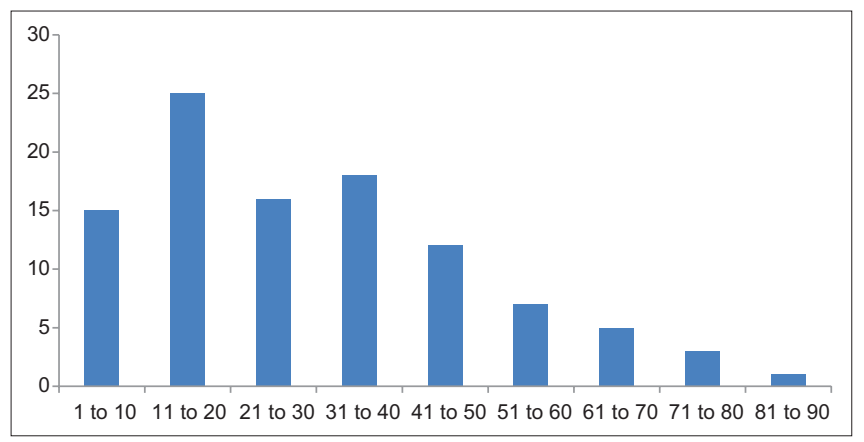

Figure 2: Age Distribution of study population $X$ axis shows age in numbers

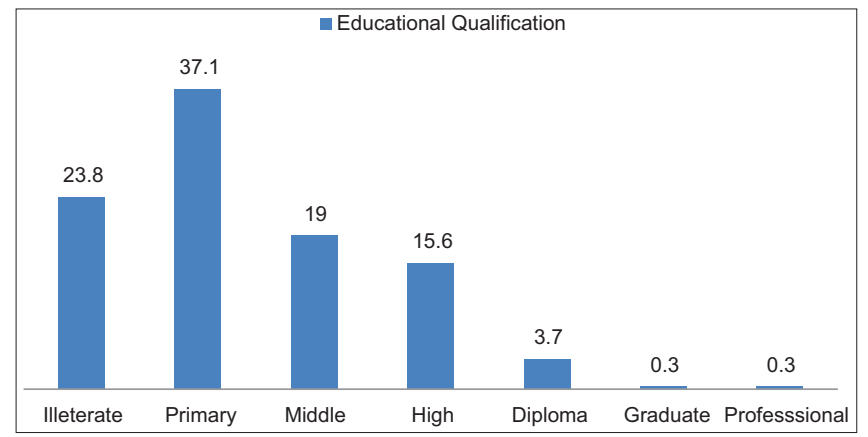

Figure 3: Educational qualification of the study population

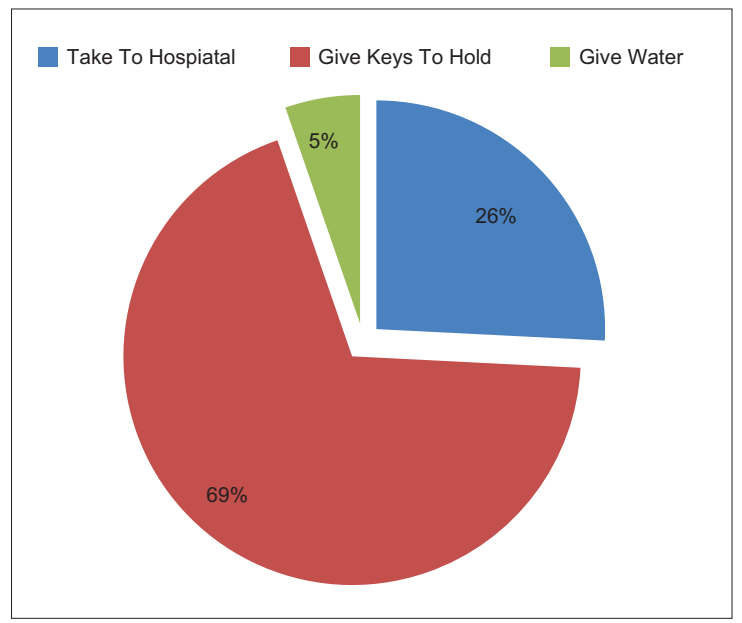

Figure 4: What would you do if you happened to see a person getting an epileptic attack?

Knowledge, attitude, and practice study results Knowledge: (01-5)

About $88.7 \%$ of people had heard about epilepsy. $68 \%$ of respondents believed correctly that epilepsy was caused by a brain disease. About $22.6 \%$ and $23.1 \%$ of the respondents thought epilepsy was a form of insanity and a hereditary disease, respectively, prevalent misconceptions were that epilepsy is hereditary $31 \%$, is contagious $12 \%$, and is a result of ancestor $\sin 21.6 \%$. Of the $88 \%$ people who responded correctly by saying epilepsy is not a contagious 
disease, $93.72 \%$ are literates indicating the importance of education.

\section{Attitude (06-10)}

About $55 \%$ of the respondents felt that individuals with epilepsy could not be properly educated or employed. Majority of them believed that epilepsy is a hindrance to happy married (42.3\%) and sexual life (54.8\%). About $36 \%$ would object to their children having contact with epileptic children. Nearly half $(36.5 \%)$ believed that society had discriminative attitude for epileptic patients.

\section{Practice (011-14)}

About $78 \%$ believed that an allopathic doctor should treat the person, and $64 \%$ believed that Ayurvedic treatment is also effective. In response to first aid measures for epileptic fits $25.8 \%$ preferred that person should be taken to a doctor, $69.9 \%$ respondents would make the person hold a bunch of keys to terminate the epileptic attack, $5.3 \%$ suggested water to be given [Figure 4 ]. Of the $25.8 \%$ who responded correctly, $51.5 \%$ are literates. $48.66 \%$ of educated responded incorrectly.

\section{Prevalence study}

Through a two-staged survey and analysis, we ascertained that about $8.7 \%$ of the study population had epilepsy. The highest age-specific prevalence rate of $28.6 \%$ occurred in the age group of $71-80$ years. Sex-specific prevalence rates are not significantly differ (53.8\% for males and $46.2 \%$ for females). About $87.7 \%$ of the KAP respondents had heard about epilepsy.

About $3.7 \%$ had a previous history of stroke. The prevalence rate for stroke on the day of survey was 3.3\%. The sex distribution for people suffering from stroke is 50-50.

\section{Discussion}

Through this cross-sectional study, we investigated the KAP toward epilepsy, point prevalence of epilepsy and stroke in a geographical area in the village hamlet of Pattaravakkam near Chennai, South India. According to our stroke registry, lot of patients from this village suffered new strokes, and the reason was thought to be sedentary lifestyle of this population. This is the main reason behind selecting this village. We believe that our study achieved the three important requirements of an ideal epidemiological inquiry complete case ascertainment, well-defined population denominator, and reasonable level of diagnostic precision. Measures we undertook well in advance of the survey to enlist participation and utilization of the questionnaire with
$100 \%$ sensitivity in the screening survey enhanced case ascertainment. Because of the lower specificity of the questionnaire, the number of people suspected of having an epileptic disorder was several folds more than the actual. Evaluation by a neurologist with special interest in seizure disorder and stroke ensured an average level of precision. Before a health education program can be established, the beliefs and behaviors of the target population with respect to the disease in question must first be identified. Lennox suggested that public health workers needed to be acquainted with the public perception on a given illness. ${ }^{[1]}$

\section{The knowledge, attitude, and practice study}

Several studies have investigated public awareness and attitudes toward epilepsy in both developed ${ }^{[2,3,12-14]}$ and developing countries ${ }^{[-6,615]}$ The results of these studies are not strictly comparable because the population studied and the questionnaires and methods used were different. The attitude toward epilepsy among the population of Pattaravakkam near Chennai was far more negative than those of developed countries [Table 3], probably due to lower literacy rate. The percentage of respondents who thought was epilepsy was a form of mental illness, who objected to their children playing with a child with epilepsy and who objected to employing a person with epilepsy were $22.6 \%, 33.5 \%, 51 \%$, respectively, in our study compared with $3 \%, 0.6 \%$ and $9 \%$ in the united states. $^{[12]}$

Nearly one-half of our respondents believed that persons with epilepsy could not have a healthy sexual life. This attitude in our population may be related to their belief that epilepsy is a hereditary and mental illness. Almost one-half of study population epileptics cannot be educated or employed as others. Most people in our study preferred the advice of allopathic although Ayurvedic medicines are accepted by a large segment of this South Indian population. Studies from developing countries ${ }^{[4,15]}$ have revealed an awareness rate comparable to those from developed countries, ${ }^{[3,12]}$ this high degree of awareness about epilepsy among the developing countries may be related to increased access to communications via telephone and television.

Based on our observations and review of the literature, it is evident that misconceptions about epilepsy, such as confusion between epilepsy and insanity and overemphasis of the role of heredity, are widely prevalent. Public attitudes toward epilepsy change slowly [Table 4]. Furthermore, awareness does not always equate to increased understanding or acceptance. ${ }^{[16]}$ These nonscientific conceptualizations of epilepsy are responsible for the sociocultural stigma and resultant 
Table 3: Comparing KAP studies to other countries

\begin{tabular}{lcccc}
\hline Inquiries & $\begin{array}{c}\text { United States } \\
\mathbf{1 9 7 9}\end{array}$ & $\begin{array}{c}\text { China } \\
\mathbf{1 9 9 0}\end{array}$ & $\begin{array}{c}\text { South India } \\
\text { (Kerala) } \\
\mathbf{2 0 0 0}\end{array}$ & $\begin{array}{c}\text { Current } \\
\text { study } \\
\mathbf{2 0 0 8}\end{array}$ \\
\hline Heard or read & 95 & 93 & 99 & 87.7 \\
Mental illness & 3 & 16 & 27 & 22.6 \\
Hereditary & 9 & 17 & 17 & 23.1 \\
Object to play & 6 & 57 & 11 & 35.6 \\
\hline
\end{tabular}

Courtesy: Reference ${ }^{12}$. KAP: Knowledge, attitude, and practice

Table 4: Comparing KAP study results to previous KAP studies in India

\begin{tabular}{lccc}
\hline Inquiries & $\begin{array}{c}\text { KAP study } \\
\text { by IEA and } \\
\text { Karuna Trust } \\
\text { 1997 }\end{array}$ & $\begin{array}{c}\text { KAP study } \\
\text { in Kerala } \\
\text { South India }\end{array}$ & $\begin{array}{c}\text { Our study } \\
\mathbf{2 0 0 8}\end{array}$ \\
& $\mathbf{2 0 0 0}$ & \\
\hline People knew of epilepsy & $76.0 \%$ & $99.0 \%$ & $87.7 \%$ \\
$\begin{array}{l}\text { People thought allopathic } \\
\text { treatment is effective }\end{array}$ & $72.0 \%$ & $78 \%$ & $80.3 \%$ \\
People who are untreated & $80 \%$ & $70-80 \%$ & $70-80 \%$ \\
\hline Courtesy: Reference ${ }^{12}$. KAP: Knowledge, attitude, and practice &
\end{tabular}

discrimination against persons with epilepsy. Persistent and effective information campaigns, therefore, are necessary to change public attitudes toward persons with epilepsy.

\section{The prevalence study}

Community-based prevalence studies have documented the crude prevalence of epilepsy from 247 to 883 , for stroke $55-150 / 100,000$ in overall population. ${ }^{[17]}$ The estimated number of persons with epilepsy in India is approximately 5.5 million, among whom approximately 4.1 million reside in rural areas. ${ }^{[10]}$ Prevalence of epilepsy is 2-25 times higher in developing countries on comparing developed countries. ${ }^{[10]}$ This difference may be apparent (misdiagnosis, inconsistent definition, failure to take into account the disease activity) or real (illiteracy, poverty, poor sanitation, inaccessibility to medical care, cysticercosis. $)^{[18]}$ Hauser $^{[16]}$ estimated an average prevalence rate of 5.2/1000 population. Some community studies from North Central and South India have shown a prevalence rates per 1000 population of 2.5 for Kashmir, ${ }^{[19]} 3.6$ for the Parsis in Bombay, ${ }^{[20]}$ and 4.4 for Bengaluru. ${ }^{[21]}$

Sridharan and Murthy ${ }^{[22]}$ recently undertook a meta-analysis of the prevalence data obtained from 20 community-based studies on epilepsy in India. After correction for heterogeneity related to interstudy variation, the overall age-adjusted prevalence rate per 1000 was 5.3 (95\% confidence interval [CI] 4.3-6.4). The prevalence rate for urban areas was 5.1 (95\% CI, 3.5-6.7), 5.5 for rural areas (95\% CI, 4.0-6.9), and men and women were 5.9 (95\% CI, 3.9-7.9) and 5.5 (95\% CI, 3.5-7.3), respectively. Regional causal factors such as cysticercosis and hot water epilepsy might have influenced the high prevalence rates reported in some studies from developing regions. ${ }^{[9,23]}$

From our study, the prevalence rate of epilepsy and stroke were was $8.7 \%$ and $3.3 \%$, respectively. This appeared to higher than the national average. The age-specific prevalence rates in our study peaked in seventh decade similar to that of developed countries, and the prevalence seems to be increasing with the age. ${ }^{[24-27]}$ However, in developing countries, the prevalence rate in elderly is lower, which may be attributed to lower life expectancy, higher seizure-related mortality. ${ }^{[9,22]}$ It is possible that there is a sampling bias, people with medical conditions are staying at home and are available for surveys.

\section{Limitations}

Community-based survey has a lot of limitations on its part against the advantages. Some of the factors limiting the accuracy of our study are:

- Inability of the people to interpret the questions rightly and respond to them

- Associated stigma may result the neglect of report of seizures by individuals

- Incidence and prevalence rates may vary if age-specific rates are not calculated, since the occurrence of epilepsy differs in different age group, sampling bias.

\section{Conclusion}

Even with increased literacy, technology, and communication devices, the KAP of people toward epilepsy is relatively low. General public education campaigns and specific school education campaigns children should be encouraged to increase the KAP toward epilepsy. The prevalence and pattern of epilepsy and stroke are on the higher side in the village of Pattaravakkam. Future research regarding the value of targeted education in improving KAP will be worthwhile.

Even with increased digitalization of the world and increased communications with television and mobile phone the KAP toward epilepsy are not up to the expected level. Literacy rates seem to have a significant effect on the KAP toward epilepsy. Solutions to this issue would be to increase literacy rates in India. In addition to increasing the overall literacy rate, there seems to be a clear need for general public education campaigns, and educating children should be encouraged to increase the KAP toward epilepsy. 


\section{Financial support and sponsorship}

Nil.

\section{Conflicts of interest}

There are no conflicts of interest.

\section{References}

1. Caveness WF, Merritt HH, Gallup GH Jr. A survey of public attitudes toward epilepsy in 1974 with an indication of trends over the past twentyfive years. Epilepsia 1974;15:523-36.

2. Canger R, Cornaggia C. Public attitudes toward epilepsy in Italy: Results of a survey and comparison with U.S.A. and West German data. Epilepsia 1985;26:221-6.

3. Jensen R, Dam M. Public attitudes toward epilepsy in Denmark. Epilepsia 1992;33:459-63.

4. Lai CW, Huang XS, Lai YH, Zhang ZQ, Liu GJ, Yang MZ. Survey of public awareness, understanding, and attitudes toward epilepsy in Henan province, China. Epilepsia 1990;31:182-7.

5. Rwiza HT, Matuja WB, Kilonzo GP, Haule J, Mbena P, Mwang'ombola R, et al. Knowledge, attitude, and practice toward epilepsy among rural Tanzanian residents. Epilepsia 1993;34:1017-23.

6. Gambhir SK, Kumar V, Singhi PD, Goel RC. Public awareness, understanding \& attitudes toward epilepsy. Indian J Med Res 1995;102:34-8.

7. Mirnics Z, Czikora G, Závecz T, Halász P. Changes in public attitudes toward epilepsy in Hungary: Results of surveys conducted in 1994 and 2000. Epilepsia 2001;42:86-93.

8. Fong CY, Hung A. Public awareness, attitude, and understanding of epilepsy in Hong Kong special administrative region, China. Epilepsia 2002;43:311-6.

9. Senanayake N, Román GC. Epidemiology of epilepsy in developing countries. Bull World Health Organ 1993;71:247-58.

10. Radhakrishnan K, Pandian JD, Santhoshkumar T, Thomas SV, Deetha TD, Sarma PS, et al. Prevalence, knowledge, attitude, and practice of epilepsy in Kerala, South India. Epilepsia 2000;41:1027-35.

11. Sands H, Zalkind SS. Effects of an educational campaign to change employer attitudes toward hiring epileptics. Epilepsia 1972;13:87-96.

12. Caveness WF, Gallup GH Jr. A survey of public attitudes toward epilepsy in 1979 with an indication of trends over the past thirty years. Epilepsia 1980;21:509-18.

13. Iivanainen M, Uutela A, Vilkkumaa I. Public awareness and attitudes toward epilepsy in Finland. Epilepsia 1980;21:413-23.

14. Baumann RJ, Wilson JF, Wiese HJ. Kentuckians' attitudes toward children with epilepsy. Epilepsia 1995;36:1003-8.

15. Chung MY, Chang YC, Lai YH, Lai CW. Survey of public awareness, understanding, and attitudes toward epilepsy in Taiwan. Epilepsia 1995;36:488-93

16. Hauser WA. Epidemiology of epilepsy. Adv Neurol 1978;19:313-39.

17. Vas CJ, Pinto C, Panikker D, Noronha S, Deshpande N, Kulkarni L, et al. Prevalence of dementia in an urban Indian population. Int Psychogeriatr 2001;13:439-50

18. de Bittencourt PR, Adamolekum B, Bharucha N, Carpio A, Cossío OH, Danesi MA, et al. Epilepsy in the tropics: II. Clinical presentations, pathophysiology, immunologic diagnosis, economics, and therapy. Epilepsia 1996;37:1128-37.

19. Koul R, Razdan S, Motta A. Prevalence and pattern of epilepsy (Lath/ Mirgi/Laran) in rural Kashmir, India. Epilepsia 1988;29:116-22.

20. Bharucha NE, Bharucha EP, Bharucha AE, Bhise AV, Schoenberg BS Prevalence of epilepsy in the Parsi community of Bombay. Epilepsia 1988;29:111-5.

21. Mani KS, Rangan G, Srinivas HV, Kalyanasundaram S, Narendran S, Reddy AK. The Yelandur study: A community-based approach to epilepsy in rural South India - Epidemiological aspects. Seizure 1998;7:281-8.

22. Sridharan R, Murthy BN. Prevalence and pattern of epilepsy in India. Epilepsia 1999;40:631-6.

23. de Bittencourt PR, Adamolekum B, Bharucha N, Carpio A, Cossío OH, Danesi MA, et al. Epilepsy in the tropics: I. Epidemiology, socioeconomic risk factors, and etiology. Epilepsia 1996;37:1121-7.

24. Hauser WA, Annegers JF, Rocca WA. Descriptive epidemiology of epilepsy: Contributions of population-based studies from Rochester, Minnesota. Mayo Clin Proc 1996;71:576-86.

25. Cockerell OC, Eckle I, Goodridge DM, Sander JW, Shorvon SD. Epilepsy in a population of 6000 re-examined: Secular trends in first attendance rates, prevalence, and prognosis. J Neurol Neurosurg Psychiatry 1995;58:570-6.

26. Forsgren L. Prevalence of epilepsy in adults in northern Sweden. Epilepsia 1992;33:450-8.

27. Olafsson E, Hauser WA. Prevalence of epilepsy in rural Iceland: A population-based study. Epilepsia 1999;40:1529-34.

\section{New features on the journal's website}

\section{Optimized content for mobile and hand-held devices}

HTML pages have been optimized of mobile and other hand-held devices (such as iPad, Kindle, iPod) for faster browsing speed.

Click on [Mobile Full text] from Table of Contents page.

This is simple HTML version for faster download on mobiles (if viewed on desktop, it will be automatically redirected to full HTML version)

\section{E-Pub for hand-held devices}

EPUB is an open e-book standard recommended by The International Digital Publishing Forum which is designed for reflowable content i.e. the text display can be optimized for a particular display device.

Click on [EPub] from Table of Contents page.

There are various e-Pub readers such as for Windows: Digital Editions, OS X: Calibre/Bookworm, iPhone/iPod Touch/iPad: Stanza, and Linux: Calibre/Bookworm.

\section{E-Book for desktop}

One can also see the entire issue as printed here in a 'flip book' version on desktops.

Links are available from Current Issue as well as Archives pages.

Click on View as eBook 


\section{Appendix 1}

\section{Questionnaire}

1. Have u ever heard a disease called epilepsy?

getting an epileptic attack?

$\begin{array}{ll}\text { (1) Yes } & \text { (2) No }\end{array}$

2. Is epilepsy a mental illness?

$\begin{array}{ll}\text { (1) Yes } & \text { (2) No }\end{array}$

3. Is epilepsy a hereditary disease?

$\begin{array}{ll}\text { (1) Yes } & \text { (2) No }\end{array}$

4. Is epilepsy a contagious disease?
(1) Yes
(2) No

5. Do you think that epilepsy is caused by ancestors $\sin$ ?

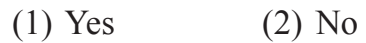

6. Do you think epilepsy is a hindrance to happy life?

$\begin{array}{ll}\text { (1) Yes (2) No } & \end{array}$

7. Can epilepsy patient lead a normal sexual life?

(1) Yes (2) No

8. Do you think epilepsy affects education of a person?

(1) Yes (2) No

9. Do you think epilepsy patients can be employed?

$\begin{array}{ll}\text { (1) Yes } & \text { (2) No }\end{array}$

10. Do you think society discriminates against persons with epilepsy?

(1) Yes (2) No

11. Do you think allopathic treatment is beneficial for epilepsy?
(a) Water
(b) Keys
(c) Admit to hospital

Modified WHO questionnaire for screening of epilepsy and stroke

1. Have you ever lost consciousness or fallen unexpectedly?

$\begin{array}{ll}\text { (1) Yes } & \text { (2) No }\end{array}$

2. Have you ever had episodes in which you have lost contact with your surroundings?

$\begin{array}{ll}\text { (1) Yes } & \text { (2) No }\end{array}$

3. Have you ever had uncontrolled shaking of hands and legs?

(1) Yes (2) No

4. Have you ever lost control of your bowel and bladder?

$\begin{array}{ll}\text { (1) Yes } & \text { (2) No }\end{array}$

5. Have you ever had episodes of blank spells with staring look or strange behavior?

$\begin{array}{ll}\text { (1) Yes } & \text { (2) No }\end{array}$

6. When awake, have you ever had very brief episodes of sudden jerking of arms and legs?

$\begin{array}{ll}\text { (1) Yes (2) No } & \text { (2) }\end{array}$

7. Are speech slurred/face droopy?

(1) Yes (2) No

12. Do you think Ayurveda treatment is beneficial for epilepsy?

(1) Yes (2) No

$\begin{array}{ll}\text { (1) Yes } & \text { (2) No }\end{array}$

8. Is one side weak or numb?

13. Would you allow your child to play with an epileptic child?
(1) Yes
(2) No

9. Is vision all or partly lost?

(1) Yes (2) No

14. What would you do if you happened to see a person

$\begin{array}{ll}\text { (1) Yes } & \text { (2) No }\end{array}$

10. Is headache severe?

$\begin{array}{ll}\text { (1) Yes } & \text { (2) No }\end{array}$ 